\title{
Stories in social work:
}

An educational resource for
evidence of practice learning

\section{Anette Bolin ${ }^{1}$ and Elsebeth Fog}

Summary: Practice learning opportunities form an integral part of studies of social work on the Social Pedagogy program at University West in Sweden and, over a period spanning several years, we have developed a reflective approach to both campus and practice learning. Over the last four years we have worked with a narrative approach to the creation of knowledge from practice learning and for examining the learning outcomes that derive from this educational process. The aim of this article is to describe and discuss the narrative approach to the creation of knowledge using the so-called 'storytelling method' as an educational resource for eliciting evidence of learning outcomes in practice learning. We have used this approach to capture the learning that takes place when students are on learning opportunity placements in the social work/social pedagogical field, both nationally and internationally. The article describes both the educational context where storytelling takes place, and the research focus on work integrated learning that led to the implementation of this pedagogical tool. We will also describe and analyse how we use the 'storytelling method' with a focus on how it can be used to 'evidence' students' learning.

Keywords: narrative methods in social work, practice learning opportunity, work integrated learning, evidence-based learning

1. Lecturer in Social Work/Social Pedagogy

2. Associate professor in Social Work/Social Pedagogy

Address for Correspondence: Anette Bolin, University West, Dept. for Social Work \& Behavioural Studies, 46186 Trollhattan, Sweden. anette.bolin@hv.se.

Elsebeth Fog University West, Dept. for Social Work \& Behavioural Studies, 461 86 Trollhattan, Sweden elsebeth.fog@hv.se

22 Journal of Practice Teaching \& Learning 7(3) 2006-07, pp.22-42. DOI: 10.1921/19641. ( $w \&$ b 


\section{Introduction}

The point of departure in the story telling method, which is described in Labonte \& Feather's handbook (1996), is that stories have played an important role in the creation of knowledge throughout history, and that professions, like any other social group also have their own stories about what they see is happening in specific socio-cultural contexts. Stories can reveal why they think something happened, what they do and how they resolve situations, what this makes them conscious of, and what they learned in particular that can be transferred to other similar ones. This means that narratives can also provide powerful ways for students to convey experience in that they provide the student with the opportunity to voice the meanings they construct from experienced events encountered in the context of the practice learning opportunity (PLOs). Used systematically, the storytelling method enables us to capture individual, evidenced-based knowledge of social work, and functions as a way to position such experientially derived knowledge into broader theoretical frameworks.

When analysing the use of storytelling in relation to evidence-based practice learning we found Parker's (2004) criteria for how to evidence practice learning of great use (pp. 96-97). Parker (2005) poses different questions to validate the learning that takes place. We have focused on the following four questions. Is the method valid, sufficient and relevant? Is it based in social-work values? Is it reliable? And, finally, is it clear and is it agreed? Addressing the first of these sets of questions, in order to see whether the pedagogical method of storytelling was valid, relevant and sufficient, we collected approximately 300 hundred case stories generated from seminars using the story telling method over a four-year period. Although the majority of these case stories emanate from Sweden, twenty came from other countries - India, Colombia, Chile, Brazil, Guatemala, the Philippines, England, Scotland, Holland, Romania and Norway.

All of the case stories were read and the questions we asked were: What subjects do they illuminate and how do they describe the social pedagogical work in different organisational settings? How do they describe the tacit organisational expectation to professional social pedagogical work and the learning process? and what ethical questions are addressed? We were also looking for critical incidents and significant events in order so see how the students were socialised into the role of a social pedagogue. 
As we had material collected over a four-year period we were looking for temporal structures, as well as social structures and structures of meanings (Mishler, 1986). Subsequently, 85 were selected for further in-depth analysis. In our deeper analysis, as well as addressing our four main questions, we also wanted to know whether the method could shed light on anti-oppressive values in social work and social pedagogy. Thus ethical issues became a prominent part of the process of analysis and we therefore focused on whether the dialectical meaning of power as both oppressive and emancipative could be detected in the case stories. Cultural awareness and culturally based communication were also specific areas of focus.

\section{The context in which storytelling takes place}

The use of the storytelling method has been developed within our Program in Social Work/ Social Pedagogy 210 ECTS Credits. Social work, focusing on social pedagogy/social education, can be characterised as an interdisciplinary field of knowledge that has its theoretical and empirical foundations in traditions of knowledge from several disciplines within the social sciences. The program provides an academic professional education for work within social pedagogy/social education. It also functions as preparation for Masters and Doctoral studies. Social work with a focus on social pedagogy/social education is the major subject in the program. The subject of research conducted in connection with this program is social work and work-integrated learning (WIL) which is one of the research profiles at University West. The pedagogic model we have developed on the Social Pedagogy program with study groups, critical reflection and evaluation of learning processes forms a basis for work-integrated learning (see more in Fog, 2003).

The reflective approach to practice is defined by Napier and Fook (2000, p.2) as

... offer(ing) some insights about a different way of conceptualizing the relationship between theory and practice, as an ongoing process in which theory and practice constantly inform and develop each other.

Our students are used to approaching their work from different

24 Journal of Practice Teaching \& Learning 7(3) 2006-07, pp.22-42. DOI: 10.1921/19641. @ wËb 
theoretical perspectives. These include theories of social work, social pedagogy, sociology, social psychology, pedagogy, political science, social policy, and social legislation, some or all of which are incorporated into the analyses of different social problems at individual, group and structural levels that are encountered during the program of education. The teaching provided has diverse perspectives, focusing on class, ethnicity, gender and power. Power can provide the opportunity to permit a shift of perspective and an awakening of cultural sensitivity leading students to an awareness of the cultural impact of the way social work and social pedagogy is exercised. In this sense one could say that it involves a transfer of culturally reflective practice into theory.

Our aim is to give the students opportunities to develop critical reflective learning processes in small study groups. The students are provided with relevant literature and then given a series of specific questions to address while they are reading the literature. Additionally, they are asked to reflect on their own experiences of the phenomena in question gained from their practice learning placements, and relate this to the theories they have encountered and, then, to write down their thoughts. By bringing their thoughts, questions, and doubts about the theoretical content of the texts they have read into the group and using it to problematise practice learning experiences, and, of course, vice versa, our students become conscious of differing, new or contradictory perspectives.

In this study group model the teacher has a participatory role, feeding their own perspectives, 'personal knowledge' and field experience into the group discussion. Each study group is, during this period of learning, followed by a mentor who supervises them in solving conflicts and reconciling different perspectives. The teacher also functions as a facilitator for the group's meta-learning processes. As personal development is seen as an important part of the education, each individual group member is asked to reflect and share their learning process with the other students in the group. Every course is evaluated in the study group and the teachers involved have a meeting, which is documented, with representatives from the student groups. In this way it is possible to obtain constructive suggestions for course development.

25 Journal of Practice Teaching \& Learning 7(3) 2006-07, pp.22-42. DOI: 10.1921/19641. (C) wEb 


\section{Practice learning opportunities}

The students undertake two periods of practice learning opportunity (PLOs) during the second and third year of their program. The first of these periods is a 15 week placement, which is followed by a 5 week period where the focus is on social organisations. During the first period the students work directly with clients, as well as conducting an in-depth study in which they describe and analyse the professional and social elements that they encounter in the institutional context in which they have their PLO.

The aim is to enable students to develop the ability to recognise, describe and understand the everyday ways of living and social circumstances of individuals and groups in order to develop an ability to understand and analyse social problems and processes. In this way, they can make use of problem-solving methods founded on institutional experience or participate in developing working methods that enable the people they are working with to use and develop their own resources.

For the in-depth study, the student is expected to need significant study time. In Sweden we normally talk about a 40-hour working week and, in the context of the 15-week PLO, students are expected to do on average of 30 hours at the placement returning to the university for three extended periods.

The second period is a five-week practice learning opportunity that is integrated into a ten-week course in organisation, social change and evaluation. Initially, the student studies theories of organisations for five weeks and is then required to use these 'organisational glasses' in the following five weeks to analyse the organisational structures and the impact these have on work with individuals and groups at their placement. The PLO studies focus on problem-identification, reflection, and the application and analysis of theoretical and methodological knowledge in practical social pedagogic work/social work. For this period the assignment is to write a case story which has been derived from the work done in the study groups using the storytelling method. If the students are going to spend their PLO in other countries, we have to be flexible, as well as spending time on careful background preparation before the student goes abroad.

We provide supervision via the use of e-mail, and the students are required to send an e-mail to us every week describing what they are

26 Journal of Practice Teaching \& Learning 7(3) 2006-07, pp.22-42. DOI: 10.1921/19641. @ wEb 
doing and the nature of the significant events that have occurred. The critical, and at times even painful events that students report on in their mails home demand careful supervision in order to help them understand the socio-cultural frame they find themselves in. This also enables them to shift their perspectives and to facilitate the process of collecting together positive experiences. At times it is necessary to make telephone calls to the student. We also correspond or talk with the supervisors at the student's PLO placement and they are able to give their evaluation of the student's learning opportunity. We ask both students and their supervisors to provide us with feedback about 'things we need to think about next time'. Further, when the students who have had experiences from other countries have returned home, we gather them together in a reflective group. We then ask them to bring their experiences from social work in different cultures to the courses they are attending, for example by focusing on power, gender and ethnicity (for more information see Fog, 2005 b).

\section{Practice learning as an element of work integrated learning: Common pedagogical ambitions and underlying theory}

The process in implementing the storytelling method has coincided with several different research projects in our department, all of which have had a focus on work integrated learning. The teachers involved in the storytelling method were all involved in the research project 'Workplace learning and creation of knowledge for professional social workers/ social pedagogy workers' where, together with a group of experienced social pedagogues and two program students, we worked with significant events and critical incidents focusing on the following questions: What is the knowledge base in social pedagogical work? What 'know-how' is demanded? and How have I become socialised into my professional role in the setting in which I am working? (Bolin, Fog \& Rönmark 2004; Bolin 2005). Some of our research results suggest that reflection as a tool needs to be systemised and documented so that, as educators, we are able to identify and understand the students' learning during their practice learning opportunities.

Using this knowledge, we wanted to gain further insights into the nature of the knowledge acquired by the students and how this knowledge survived during subsequent educational processes. In

27 Journal of Practice Teaching \& Learning 7(3) 2006-07, pp.22-42. DOI: 10.1921/19641. () wEb 
another research project concerning the transferability of knowledge (Fog 2005 a) we explored whether students' education is influenced by the knowledge and 'know-how' they derive experientially during their PLOs. The research thus focused on the orientation of their education as part theoretical and part experiential. In the study we sought to find answers to two specific questions: 'what does the student learn during her/his applied studies?' and 'how can experiential knowledge gained from an institutional context function as a springboard for a reflective process that can contribute to gaining new knowledge thus enabling the social worker to handle social work in a changing world?' This study was inspired by the research of Fook, Ryan and Hawkins (2000), who argue that skills are developed in the professional field in which the individual works, and that social workers learn to create and develop knowledge from specific situations and then to transfer this knowledge to other analogous situations.

In particular, we wanted to know whether PLOs contribute to the creation of knowledge about the world of social work around us, and the paradigms our colleagues are working from. How did the students inductively create meanings from each new situation and how did they translate prior thinking into terms which made them more easily engage with a new situation? Fook, Ryan and Hawkins (2000, pp.190-191) call this the 'transferability of knowledge', that is to say, the ability to modify, change and develop theory and knowledge so it can be made readily relevant in different contexts and where the emphasis is on relevance.

It is the skill of being able to apply old knowledge in new situations, or creating new knowledge to fit new contexts, which is the essence of transferability, and which enables expert to deal with change and uncertainty. (Fook, Ryan \& Hawkins, 2000, p.190)

Forty of the students' in-depth studies generated from their 15 week PLO were analysed. It was found that many encompassed 'traditional' social pedagogical arenas where the focus is often on work and treatment methods. A minority of studies, however, had a focus on new arenas for social pedagogy, such as schools, and, in these studies, the focus was more on cooperation, professional relationships, inter-professional collaboration, ethics and the effects of intercultural encounters.

When it came to theoretical perspectives on the chosen subject, the students chose literature from the previous courses that they had studied.

28 Journal of Practice Teaching E Learning 7(3) 2006-07, pp.22-42. DOI: 10.1921/19641. @ wE-b 
This was partly because it was convenient 'to play it safe' or was relevant to their subject of enquiry, but very often because the literature was of a social philosophical nature, i.e. literature about relationships, values, and ethical questions that could help them to analyse socio cultural and ethical dilemmas. The students also made use of literature about everyday life and social pedagogical competence in combination with literature that describes institutional working method, such as structured family therapy.

The research project outlined above was conducted simultaneously with the storytelling method during 2003. Our focus on students' learning during PLOs was both practical and theoretical. This was an important factor since our ambition has been to develop new insights into how the reality of theory and practical skills are intertwined with one another. As Galloway (2007) puts it, we need to view the research endeavours as an intimate form of social work practice rather than as something separate from the 'real' everyday, busy, hands-on or 'messy' business of social work. Thus we wanted to develop an overarching focus on the concept of work integrated learning.

\section{Storytelling as a pedagogical tool}

Labonte and Feather (1996) describe how the systematic use of stories in program planning and evaluation first began in international development work. International policy makers working in the field of international health found this method useful when they had to evaluate and develop health promotion programs. Using the method directly on the ground, aid workers realized that they needed to respect the oral cultures in many areas of the developing world, discovering that local peoples had an amazing knowledge about their lives and the environment that conventional research could not tap into. As Labonte $\&$ Feather demonstrate,

Stories or narratives, are powerful ways to convey experience because only the narrator can give voice to the particularities and meanings that make up our lives. (1996, p.6)

Another source of inspiration for Labonte and Feather came from

29 Journal of Practice Teaching \& Learning 7(3) 2006-07, pp.22-42. DOI: 10.1921/19641. (C) wEb 
the contemporary women's movement where storytelling was used to create knowledge about the individual woman's life situation seen in a social context. In consciousness-raising circles, women were asked to tell their story and share their experience and, from that, they were able to learn from each other and develop a body of knowledge about women's oppression and empowerment. In the circles the method of taking turns was developed. The woman had the opportunity to speak without being interrupted in a trusting climate where the listeners were so close that they could ask the right questions in order to understand what was told. This enabled them to fill in the gaps in the story while maintaining a distance so that they could critically reflect about the story in its historical, ethnic, gender, and class context. In some of the circles the women's individual and social life histories were systematically documented which gave the effect that their own subjective biography assumed an objective character because the individual history was linked to the overall social history of an epoch (Mies, 1983).

As Noble (2201) argues, narratives can be used as an exploratory tool that students and teachers can use to make sense of the dilemmas, problems and particularities of teaching the melding of theory and practice in social work. Noble concludes that the use of narratives facilitates the link between theory and practice and challenges the uncertainties of deficiencies and uncertainties of expert knowledge.

Paulo Freire (1968) has also developed storytelling as a method in education where the participants share their experiences in their own words and by, so doing, are able to name their own worlds. The stories are listened to and respected by others and by sharing the stories the collective consciousness of the storytellers is raised and they are able to develop an understanding of the context where the story takes place and from where they can start to frame the story.

Thus, drawing on Freire's ideas, we first wanted our students to share significant events that they had experienced in order thereafter to frame these and in so doing raise their collective consciousness about the meaning they construct from an experienced event encountered in the context of their PLO.

30 Journal of Practice Teaching \& Learning 7(3) 2006-07, pp.22-42. DOI: 10.1921/19641. @ w\&b 


\section{The storytelling method concretized}

\section{The story theme}

Every story has a theme, a plot (something that happens), a context, a voice and a narrative form (i.e. a beginning, middle and end). All of these are of importance in the storytelling method but, most of all, it is the theme that assumes the greatest importance due to its generative nature (see Freire 1968, 1993). The first year that the students shared their experiences from their practice learning (2003) it was decided that the stories should focus on collaboration and how to handle ethical problems in organisations and. Here the themes generated were conflict and power. In the second year (2004) the generated themes that were given special attention were communication, collaboration, learning and knowledge. In the two subsequent years $(2005,2006)$ the themes were socialisation into the profession, meeting clients and being a social work student. We decided on specific themes in order to see whether the focus of the stories would increase the occurrence of descriptions of the students' own role in their learning process and to enhance the visibility of the students themselves in their stories.

\section{Time schedule}

The story telling method takes place over a three-day period at the university. The first day takes place at the beginning of the course in organisation, change and evaluation (i.e. before PLOs start). Day two and three take place during the students' PLO.

Day One

At the start of the first day the storytelling method is introduced. The core element is the story itself, and that it should lead to a generative theme, that is to say a theme that can open up opportunities for many different associations and reflections. Thus, quite a lot of time is spent discussing the elements of a story and the characteristics of a 'good' story. For example, in a 'good' story, the plot is of great importance. Things

31 Journal of Practice Teaching \& Learning 7(3) 2006-07, pp.22-42. DOI: 10.1921/19641. (C) wEb 
have to happen. These things take place, of course, in a particular context and are usually caused by someone (maybe by the story's protagonist) and experienced by others (either the protagonist or those close to her) and which are, thereafter, told by someone, i.e. the narrator or storyteller (Hydén \& Hydén, 1997).

The story should be chosen for a particular purpose and it should relate to the theme that has been provided, i.e. collaboration. Furthermore, the story should come from the student's own experience and, most importantly, it should contain key elements such as description, explanation and reflection. On the first day we also give students practical instructions about how to proceed. For example, we might tell students to go to their work-placements and think about the types of generative theme that they might want to choose. Then having spent say a week doing this, they could begin to write a case story with a particular focus on something that they think is important to share with others. Students are also instructed that their story should be between one and two pages in length.

In our experience the students are often quite confused about, or even sceptical, about the idea that their own story should be sufficient evidence of learning during the PLO. For example, we encourage them not to use theoretical references, but instead to formulate how they themselves perceive and understand the situation they chose to describe in their story. We start from the proposition that knowledge is a social construct and that the source of the knowledge they draw from in understanding their story is equally valid. Thus, there is no difference in status between things that their 'granny' always said, or whether they have read something in a research article. We also go through the process of the storytelling method. Here we have found that students often find it difficult to conceptualise the process and to comprehend what it will involve. This experience counts for us, as teachers, as well and we found that it took some time before we ourselves could fully understood how to use the method.

We also discovered at a fairly early stage that the manual needed to be adapted to fit into our particular socio-cultural context. In short, the process of the storytelling method can be summarised as follows:

1. Introducing the method

2. Choice of a theme

3. Preparation of a case story

32 Journal of Practice Teaching \& Learning 7(3) 2006-07, pp.22-42. DOI: 10.1921/19641. @ w\&b 


\section{Sharing of case stories \\ 5. Creation of an insight card \\ 6. Creation of categories \\ Construction of theory}

Day Two

The second day we focus on the story itself. The students again return to the university where they are divided into small groups of five to six students where they share their case stories with the others in the group. The students are asked to use a form of 'structured dialogue' (i.e. a narrative form for the story that is comprised of recognisable stages such as beginning, middle and end and that can lead to questions raised by the other members of the group). Later on during the day, after all the stories have been read and discussed in the groups, the students are asked to create so-called 'insight cards'. The insight cards function as a form of documentation which contain the insights that other students' questions have given rise to. Thereafter, at the end of the day, students are told to go home and rewrite their story.

The teacher is present in the group when the first story is told, and acts as a model for formulating questions as a means of creating a structured dialogue. In particular we emphasise the importance of careful listening, decoding the structure of the story, and the use, in the subsequent discussion, of open questions inviting others to think and reflect. At times the teacher, or indeed one of the students, stops the presentation for a 'meta reflection pause' to recapitulate upon what is taking place (both in the story and in the study group). When the storyteller tells her story, questions are raised about the story and, when a question is asked, no continued dialogue or responses are allowed without first offering other group members the opportunity to also ask questions.

After the story has been told, it is followed by a short reflection circle about the triggers that the other group members have identified. It is here that they first get the chance to share their own experiences. A more regulated structure of questioning, or 'structured dialogue' follows this. Here, questions asked have to fall into one or more of a number of predefined categories, where the purpose of the questions is to clarify the story.

What do you see happening here? (description)

33 Journal of Practice Teaching \& Learning 7(3) 2006-07, pp.22-42. DOI: 10.1921/19641. @ wE-b 
Why or how come you think it happened? (explanation)

So, what have we learnt from our own experiences? (synthesis)

Now what can we do about it? (action).

The 'why' gives an explanation that offers an understandable and credible account for why things happened as they did. It invites discussions on causes and enables students to begin to interpret or make sense of what has been described. The purpose of the 'so, what' question - what have we/you learnt, what remains confusing - is to try to achieve a synthesis by encouraging the storyteller to summarise what she/he has learnt from the experience. The question 'now what' is designed to enable students to consider what possible action could be taken - what could be done differently next time and what might be the next set of actions? This level of questioning translates those elements that the group regards as being significant about the case story into new actions.

For each story, the students take different roles: that of storyteller, facilitator, timekeeper and story recorder. These roles circulate amongst the group.

The storyteller tells the story. Story listeners are asked to listen and make brief notes and, after the story has been told, to share these with other members of the group. The group share their reflections on what it was like to hear the story and how the story connects to their own experience.

The facilitator and the timekeeper initiate the process so that all the participants in the group get a chance to tell their story and to ask questions.

The story recorder writes down the questions and responses that the other students have and gives these to the storyteller. That is what we call insight cards.

Time usually afforded to the entire process for each story is between 60 and 90 minutes. The storyteller has to tell the story in 5-10 minutes. The reflection circle lasts for about 10 minutes, the structured dialogue can take 25 - 45 minutes, and, finally, the construction of the insight cards can take up to 20 minutes.

At this point the student then takes the documented feedback on the insight cards home and reformulates her story using the insights that the other group members have given her and reflects upon what she learned from this process.

34 Journal of Practice Teaching \& Learning 7(3) 2006-07, pp.22-42. DOI: 10.1921/19641. @ wEb 
Day Three

The third day, which we call the 'knowledge development day', involves constructing categories from the insight cards and making connections to relevant theory. We explain to the students that this is the day where, together, we can develop understandings about theory via practice learning and, consequently, to understand the importance of such theories for social pedagogy. We also explain that this exercise will be useful for them when they are going to do their own independent research and when writing their final undergraduate thesis.

In practical terms, during this third day in which experiences and theory are synthesised, we gather together all of the students' insight cards and place them in a classroom, where students can then walk around and read them. It is at this stage that categories can be created and, thereafter, theories about practical social work, ethics and values can be related and indeed constructed. When creating categories the students receive the following instructions:

- Look at the insight cards and ask questions:

- Ask yourself what you see

- Ask yourself why you think these statements belong together

- Ask yourself how groups of statements can relate to specific themes (i.e. 'socialisation as a social worker')

- Try to give each category a name (since the categories ought to say something about the theme, the name should be the 'glue' which binds all the cards together - for example if the theme is 'meeting the client' the category could be 'policy and guidelines', 'professionalism', or 'reflection').

When the categories are created, the process of using theory to link the categories together can begin. In one example, for instance, use of the theme 'conflict' led to the development of the following categorises:

- Responsibility and accountability

- Consequences of conflict

- Clear communication in social work

- Social work as a coordinator in communication

An example of a theory note using the theme 'conflict' could be:

'A conflict occurs often when it is not clear who is responsible and accountable for

35 Journal of Practice Teaching \& Learning 7(3) 2006-07, pp.22-42. DOI: 10.1921/19641. (C) wEb 
... the work being done (or not being done). It is difficult to know who is responsible or accountable if this has not been decided from the beginning. Everyone needs to feel responsible and accountable for their part of the work and many conflicts can be avoided'.

\section{Outcomes and evidence}

The act of storytelling trains students in the art of being close but yet distant at the same time. They have to learn to tell their story so others can understand what it is all about, as well as to listen very closely so they can help others to arrive at insights about the situation in focus and to learn how to act next time such a situation arises. By entering into a dialogue with others, the student learns to listen, focus on what the other says, to ask clarifying questions of the storyteller, to reflect critically about the story and to develop an openness that allows thoughts to be shared with others.

In this way the student can help the others gain insights into what happened, why it happened, how it happened and the self-insight into how she herself had reacted. The what, why and so what questions are asked in rounds so each student asks and shares their thoughts oneby-one, whilst the others listen. The synthesising process helps them to analyse, create categories and construct knowledge that they can use when undertaking research for their degree project (undergraduate thesis) as well as for use in future working life. Moreover, it also makes them conscious of the value of the oral story so that they learn to respect stories as a means of conveying information and constructing knowledge.

Storytelling can thereby become a process of conscientization (Freire 1968, 1993) meaning that it raises awareness of what students pay attention to and how this can be directed by personal values and theoretical perspectives. By framing the story in the light of social, political and economic contradictions students can become conscious of the influence on social work of local traditions and the values in national social politics. For those students who have been to other countries this process can often become a process of comparative social policy.

36 Journal of Practice Teaching \& Learning 7(3) 2006-07, pp.22-42. DOI: 10.1921/19641. (c) wEb 


\section{Values in social work}

The case stories about communication, collaboration and power showed that the theme of power often focused on the role of supervisors, covering issues such as participation roles, supervisors' use of body language and planning processes. Some of the case stories illustrated examples of institutional segmentation; here students learnt that, when participating in a planning meeting, where you have to decide the future of a client, it is important to know what your role is and what you can and cannot decide. It is also necessary to know how much power you have and what you can delegate to other colleagues or indeed to the client. To do this, it is important to have a good knowledge of legislative requirements and the praxis of the bureaucracy in which you are working.

Another commonly arising theme was how to behave when you are the client's advocate and how to provide help and to support the client's self help, as well as working with client advocacy, and, importantly, how to accomplish all of this without oppressing the client. Students reflected on two forms of language; the implicit and the explicit. One form of language is used in situations where you draw on your cultural understanding and awareness and competence. The other is used when you have to explain the situation to the client and where the implicit is made explicit and is analysed, and where you show your understanding of the situation.

Cultural awareness about ethnic and institutional oppression were also the subject of discussion, with some students working with generative themes (for example power and powerlessness) that they had started during their previous 15 weeks of applied studies. It emerged that it is often painful to admit that it is sometimes necessary to use power in social pedagogical work. In such situations it is important to be conscious of the nature and dynamics of power, when its use is unavoidable, and the conditions under which it is exercised. Another focus was on how the lack of resources can engender situations where power has to be used. Here reflections were made that we often talk in terms of the power of the professional, but seem to forget how powerful the client can also be.

An attempt to account for the relevance of the themes for learning about social work values is made in the following list:

- Importance of communication - both within the profession, with

37 Journal of Practice Teaching \& Learning 7(3) 2006-07, pp.22-42. DOI: 10.1921/19641. @ w\&b 
other professionals and with service users.

- Awareness of power in relations, both in an educational context (between teacher, student and supervisor) and in hands-on social work (between the social worker and service user).

- Importance of ethics in social work and social work teaching, both for teacher, student, supervisor, social worker and service user.

- Awareness of power inequalities in relations, e.g. use of professional language, use of organisational resources,

- Awareness of equality between people, value statements about people with disabilities, misuse problems (alcohol, drugs, sex and gambling), views on people in training

- Awareness of cultures and social constructions such as, for example, different traditions in views on children's rights, children's best interests and the importance of learning

- Awareness of how different social political systems influence the values of social work.

\section{Ethical issues}

When it came to vulnerable groups i.e. social work done in the probation service, in prisons, in psychiatric units or with people with psychiatric or intellectual disabilities, the question of the exercise of professional power is a frequent issue. Other issues included the question of influence, the right to participate in decision-making, participation and democratic means of communication. The students reflected upon how, as professionals, they could use their power for the empowerment of the underprivileged. Reflections were also made on how, at the same time, power could be used to oppress people and result in ensuing feelings of helplessness and powerlessness, on the part of the social worker, when you can't reach the person you are supposed to work with. Some wrote about how the institution and the professional both influence each other, and how individuals are formed by institutional rules, both written and tacit, and understanding how different institutions have different practice norms. Some students considered the question of how young people are able to manage in a free environment when they have to follow institutional rules. An issue that formed a common point of reference in all of these stories was the importance of establishing and maintaining good relationships with clients and colleagues.

38 Journal of Practice Teaching \& Learning 7(3) 2006-07, pp.22-42. DOI: 10.1921/19641. @ wE्b 


\section{Is the method reliable?}

To answer the question 'is the way we are working clear and can it be understood by others?' The students and teachers have evaluated each course over a four-year period. Here follows a yearly account of evaluations and reflections.

In 2003 the students shared their experiences from their practice learning and decided that the stories should focus on joint themes of power, cooperation and conflict. Some of the students continued to analyze the dialectic of power in their undergraduate degree projects. On the other hand, some of them didn't really understand why they had to work like this until we started the synthesizing process, as this quotation from an evaluation makes clear:

Our knowledge is anchored in reality and it is helpful not only to put my own knowledge into words, but also to share it with others and see it in another perspective from a number of shifting positions. (2003)

When the students evaluated the method with regard to social work values they remarked on the fact that they found it useful and that it was a good way of vitalising the concepts of respect, power and seeing the person in their contextual and socio-cultural situation. It was, however, a method that required time and many students felt that it could have been more usefully used during the 15 weeks of applied studies. They also suggested constructive changes and many of these suggestions were implemented in subsequent versions of the module. The evaluations showed that we had to revise the instructions so they were more specific. The students also felt it was important that the teachers 'followed the manual' when supervising the groups and indeed the importance of keeping to two or three subjects that are examined from different perspectives.

In 2004 all of the groups found it to be a rewarding way of working where they learned a lot and found it exiting to share and analyse work experiences without having to relate to theory. A quote from the course evaluation expresses this view rather clearly:

Good that one had to think for oneself, good to see what is happening in a wider perspective, good that we learn to listen to each other. We should have learned

39 Journal of Practice Teaching \& Learning 7(3) 2006-07, pp.22-42. DOI: 10.1921/19641. (C) wEb 
this method earlier on. (2004).

In 2005 the theme was about situated and contextual learning: how the students are socialized into the organisation's life and how to approach the client. We could see that the students had difficulties in getting the learning process into perspective. In some groups the discussion turned out to focus on 'good' or 'bad' supervisors and it was difficult to get the students to talk about the situational interaction processes in a contextual setting. It was also difficult to get them to focus on the culture of the institution.

The majority of the students had difficulties in seeing how the theme was connected to the field placement and the course on organisational theory. They found it difficult to connect the theories they had read about with their own experience. We learned too that we had newcomers in the teachers' group who we had to supervise and who needed to follow more experienced colleagues. In 2006, the storytelling method was, in contrast to previous years, used during the 15-week field placement where students were trained in listening to and asking questions of the storytellers about power and ethical questions. Group members focused on questions such as "what did you learn about your own reactions - from the contextual learning by observing or by being part of the situation, and how can you transfer this to other similar situations?'

We also continued to work with the students' learning process during their PLOs in organisational settings, which will also be the theme for 2007. A student who returned to a children's home in Bolivia where she had been a volunteer seven years ago evaluated her work-integrated learning. She remarked that she suddenly that recognised that she was seeing different things and processes through her 'organisational glasses' and that she was observing from an organisational perspective.

We have also experienced that the method can raise students' consciousness about how they are part of the situation and that there are dilemmas in such learning situations, especially if the students bring their own biographies into the situation. It must be remembered that it is a learning situation - and not a therapeutic one - and the boundary between professional space and private space needs to be clearly defined. Boud and Walker (1998) remind us of the tricky ethical dilemmas present in such learning situations. They contend 'that there is a need for boundaries on what outcomes of reflections are to be shared with others and these boundaries should be clarified from the start' (p.199)

40 Journal of Practice Teaching \& Learning 7(3) 2006-07, pp.22-42. DOI: 10.1921/19641. (C) wEb 
To summarise, we can now see that the method is necessarily resourceintensive. We noted, in 2006, that when, after initial instruction, we left students on their own, some groups did not take it seriously because they could not see the value of it. Others took it very seriously once they had grasped the method. Some students showed analytical abilities, which we see materialising subsequently in their degree projects. Others were quite unstructured in their thinking and, unfortunately, still are. We also learned that the teachers involved have to be clear and give specific written instructions. They have to follow the groups and help them to pause and talk about what is going on as part of a process of meta-communication. We also have to be more specific about what it means to work from a manual based on methods because this is what reality increasingly involves. We have experienced the importance of evaluation where there must be space for questioning the method and critical voices so we can continue to improve our working practice in the future.

\section{References}

Bolin, A. (2005) Learning 'at work' during social work education: An example of practice learning opportunity from Sweden, Journal of Practice Teaching in Health and Social Work, 6, 2, 6-23

Bolin, A., Fog, E., and Rönmark, L. (2004) Situerat lärande på socialpedagogiska yrkesfältet. [Situated learning at the field of socialpedagogy] in J. Theliander (Ed.) Arbetsintegrerat lärande [Work-integrated Learning] Lund: Studentlitteratur. pp. 155-178

Boud, D. and Walker, D. (1998) Promoting reflection in professional courses: The challenge of context. Studies in Higher Education, 23, 2, 191-207

Fog, E. (2003) Work -integrated learning in residential care. European Journal of Social Education A Periodical of FESET, 4, 63 -72

Fog, E. (2005a) The transferabilility of contextual learning. in E. Cedersund, and L. Eriksson (Eds.) Socialpedagogiken i samhället. Rapport från en nordisk forskningskonferens vid Linköpings universitet, Campus Norrköping 11-12 november 2004. Norrköping SPIS report no. 2. pp.67-83.

Fog, E. ( 2005b) When the well known meets the unknown. European Journal of Social Education A Periodical of FESET, 8/9, 83-93

Fook, J., Ryan, M., and Hawkins, L. (2000). Professional Expertice: Practice,

41 Journal of Practice Teaching \& Learning 7(3) 2006-07, pp.22-42. DOI: 10.1921/19641. @ wEb 
theory and education for working in uncertainty. London: Whiting \& Birch

Freire, P. (1968) Pedagogy of the Oppressed [New revised ed. (1993) trans. M.B. Ramos] Harmondsworth: Penguin

Galloway, G. (2007) Reviewing seminal experiences: Understanding through engagement with every day practices to build knowledge. Research based field education placements: Not so boring after all! [Presentation at 6th International conference onThe 6th International Conference for Practice Learning and Field Education in Health and Social Work, York, 9th-11th July]

Hydén, L-C. and Hydén, M. (1997) Att studera berättelser: samhällsvetenskapliga och medicinska perspektiv. [The study of Narratives: Perspectives from social science and medicine] Stockholm: Liber

Labonte, R. and Feather, J. (1996). Handbook in using stories in health promotion Practice, Prairie Region Health Promotion Research Center. University of Saskatchewan, Canada.

Mies, M. (1983) Towards a methodology for feminist research. in G. Bowles and R. Duelli Klein (Eds.) Theories of Women's Studies. London: Routledge \& Kegan Paul. pp.117-139

Mishler, E.G.(1986) Research Interviewing: Context and narrative. Cambridge, MA: Harvard University Press.

Napier, L. and Fook, J. (Eds.) (2000) Breakthroughs in Practice. Theorising critical moments in social work. London: Whiting \& Birch

Noble C. (2001) Researching field practice in social work education. Integration of theory and practice through the use of narratives. Journal of Social Work, $1,3,347-360$

Parker, J. (2004) Effective Practice Learning. Exeter: Learning Matters

Parker, J. (2005) Should you encourage students to assess themselves in practice learning? A guided self-efficacy approach to practice learning assessment in Journal of Practice Teaching in Health and Social Work, 6, 3, 8-30

42 Journal of Practice Teaching \& Learning 7(3) 2006-07, pp.22-42. DOI: 10.1921/19641. ๑ wE्b 